\title{
CMR assessment of hypertrophic cardiomyopathy with restrictive phenotype
}

\author{
Minjie $\mathrm{Lu}^{1 *}$, Shihua Zhao ${ }^{1}$, Yan Zhang ${ }^{1}$, Bailin $\mathrm{Wu}^{1,2}$, Jing $\mathrm{An}^{3}$ \\ From 18th Annual SCMR Scientific Sessions \\ Nice, France. 4-7 February 2015
}

\section{Background}

Hypertrophic cardiomyopathy is a heterogeneous myocardial disorder with a broad spectrum of clinical presentation and morphologic features. Recent reports indicated that some patients with restrictive cardiomyopathy. Comprehensive cardiac magnetic resonance imaging of the restrictive phenotype in HCM patients has not been fully evaluated. The purpose of this study was to investigate the CMR characteristics of hypertrophic cardiomyopathy $(\mathrm{HCM})$ with restrictive phenotype.

\section{Methods}

19 patients of HCM with obviously restrictive characteristics and 19 patients with non obstructive HCM, matched with age and gender, were collected. The differences in clinical features, CMR morphological characteristics, and the function parameters were retrospectively compared of the two groups. The paired sample $t$ test and $X^{2}$ test/Fisher's exact probability method were used for statistical analysis.

\section{Results}

Restrictive phenotype of patients with HCM have more severe clinical conditions including sustained atrial fibrillation, pericardial effusion, and lower heart function classifications compared with controls; The left and right atrium diameter were $55.79 \pm 5.34 \mathrm{~mm}$ and $61.33 \pm 11.05 \mathrm{~mm}$, which were significantly greater than the controls $(\mathrm{p}<0.001)$; The segments with late gadalinum enhancement were $7.68 \pm 2.98$, which were significantly more than that in controls $(5.10 \pm 2.77, \mathrm{p}=0.008)$. The left ventricular end-diastolic volume index, the cardiac index, and the left heart ejection fraction of patients with restrictive phenotype were all significantly less than those of the controls.

${ }^{1}$ Magnetic Resonance Imaging, Fuwai Hospital, Beijing, China Full list of author information is available at the end of the article

\section{Conclusions}

Restrictive phenotype is a special subtype of HCM. The CMR features include mild-to-moderate left ventricular hypertrophy, huge atrium, normal or small left ventricular, pericardial effusion and a wide range of late gadalinum enhancement, often with severe clinical symptoms and poor prognosis. MRI has important application value in the diagnosis of the disease.

Authors' details

${ }^{1}$ Magnetic Resonance Imaging, Fuwai Hospital, Beijing, China. ${ }^{2}$ Radiology, the Second Hospital of Hebei Medical University, Shijiazhuang, China. ${ }^{3} \mathrm{MR}$

Collaborations NE Asia, Beijing, China.

Published: 3 February 2015

doi:10.1186/1532-429X-17-S1-P299

Cite this article as: Lu et al:: CMR assessment of hypertrophic

cardiomyopathy with restrictive phenotype. Journal of Cardiovascular Magnetic Resonance 2015 17(Suppl 1):P299.

Submit your next manuscript to BioMed Central and take full advantage of:

- Convenient online submission

- Thorough peer review

- No space constraints or color figure charges

- Immediate publication on acceptance

- Inclusion in PubMed, CAS, Scopus and Google Scholar

- Research which is freely available for redistribution 